\title{
The Challenges and Measures for Internship among Fourth-Year Students in the Department of Lifelong Learning and Community Education at the University of Namibia
}

\author{
Lydia Shaketange, Alex Tubawene Kanyimba, Elizabeth Brown \\ University of Namibia, Windhoek, Namibia \\ Email:1shaketange@unam.na, akanyimba@unam.na,ebrown@unam.na
}

How to cite this paper: Shaketange, L., Kanyimba, A. T., \& Brown, E. (2017). The Challenges and Measures for Internship among Fourth-Year Students in the Department of Lifelong Learning and Community Education at the University of $\mathrm{Na}$ mibia. Creative Education, 8, 2258-2274. https://doi.org/10.4236/ce.2017.814155

Received: September 18, 2017

Accepted: November 19, 2017

Published: November 22, 2017

Copyright $\odot 2017$ by authors and Scientific Research Publishing Inc. This work is licensed under the Creative Commons Attribution International License (CC BY 4.0).

http://creativecommons.org/licenses/by/4.0/

\begin{abstract}
Internship is practice-based learning that forges a close relationship between universities and workplaces. The aim of this study was to investigate the challenges and measures for internship among fourth-year education students in the Department of Lifelong Learning and Community Education (DLLCE) at the University of Namibia (UNAM). The study embraced a mixed methods approach because it sequentially employs quantitative and qualitative research procedures. According to the interns, academic challenges that they face are the lack of support from the internship agency and lack of materials to do assignments from the academic supervisors. The logistical challenges pertain to lack of transport and accommodation facilities. Interns expressed need to develop their skills for writing, leadership and management skills as some of the measures to make internship an effective learning path. They also put forward four categories of measures that can be applied to ensure that internship becomes a valuable path of learning for students in the DLLCE. The categories relate to the orientation of students, enhancing student knowledge, developing agreements with agencies and procedures relating to the internship process. Based on the testimonies of the interns, it is recommended that fourthyear students be adequately orientated before they enter an internship and that the internship process be made explicit. Moreover, according to these testimonies, there is a need to give assignments that integrate how to transfer learning pertaining to leadership and management skills into places where student interns undertake their internship and that lecturers must teach the skills of minute taking, report writing, formal letter writing and proposal writing. Finally, the DLLCE should use the UNAM's office of External and International Relations to enter into formal agreements with the agencies of
\end{abstract}


attachment. This would help students to identify the agencies that relate to the DLLCE and hence have enough time to address the academic and logistical issues of interns.

\section{Keywords}

Lifelong Learning, Internship Training Community Education, Development Education

\section{Introduction}

Namibia's Vision 2030, which is a long-term plan for sustainable development, sets a target that by 2030 Namibia should have joined the ranks of high-income countries and afford its entire citizens a quality of life that is comparable to that of the developed world (Namibia. Office of the President, 2004). Namibia Vision 2030 calls for rapid economic growth to be accompanied by the development of human capital. It acknowledges training and capacity building as two of the ways in which the goals of the vision could be achieved. After years of implementing the Namibia Vision 2030, some objectives especially in the health sector have been achieved while the objective of creating a well-educated and skilled population is lagging behind (New Era New Paper, 2015). This scenario calls for higher education institutions to provide educational opportunities to enhance human capital development and knowledge and to impart skills required in the labour market.

The University of Namibia (UNAM) was established by the University of Namibia Act, 18 of 1992 (Namibia, Government, 1992). UNAM has a mandate to provide quality higher education through teaching, research and community services. The university's mission is aligned with the need for the production of productive/skilled and competitive human resources, capable of driving public and private institutions towards a knowledge-based economy, economic growth and improved quality of life (UNAM-CEQUAM, 2012).

In an effort to provide higher quality education a number of faculties and departments exist at UNAM. These are tools to guide the empowerment process that provides opportunities to enhance learning opportunities for students at the higher education institutions. The Department of Lifelong Learning and Community Education (DLLCE) in the Faculty of Education was established in 1996 to provide students with the opportunity to grow and enhance their career development so that they could contribute to the achievement of Vision 2030. Internship, one of the courses offered by the Department, is a practical skills training enterprise designed to bridge the gap between the theoretical world of academic enterprise and the world of professional practice in the field of community education (Lauber et al., 2004). Internships offer the on-the-job training essential for the world of work and expose final year students to real work conditions which help them acquire practical skills, such as how to work in a team, 
time management, problem-solving and how to work with customers, learners and as community members. The exercise provides students with practical skills and experience of working on projects alongside agency experts. During the internship, each student is allocated two supervisors, namely a site and a department supervisor respectively. These supervisors are responsible for monitoring and guiding the interns in the practical attachments. Prior to the departure of students to the field, they are briefed on the expectations of the internship programme. Students are given letters of introduction from the university indicating the activities which they are capable of handling. The site supervisors are required to fill in an assessment form they received during a visit by the department supervisor or which was posted on the UNAM portal. These forms aim to give site supervisors a chance to make a general assessment of the interns, which involves the evaluation of their performance. The form includes questions that collect both quantitative assessment data and qualitative comments on each student supervised. University staff will visit students at the organisations of attachment to find out what activities students are involved in and their general conditions during attachment. Students are also required to provide a report on their internship experience, including the recording of their daily activities in a portfolio. They also need to sign a register of their weekly attendance in their personal diary, which is countersigned by the site supervisor as proof of the execution of the activities by the intern. After the internship, students give feedback and share their experiences with fellow students.

This paper builds on the need to enhance the provision of quality internship from the perspective of the students in the DLLCE at UNAM. This discussion is important because the internship, like all other curricula of the Department, is upgraded every five years, as per the University's criteria for quality standards and the curriculum. The researchers use the results of this exploration to suggest a mechanism to organize the educational internships in a manner that ensures quality provision of internship among the students of the DLLCE at UNAM.

This paper has six parts. The first part presents the statement of the problem. This is followed by the conceptual and theoretical framework. The third part presents the methods of research, which is followed by the presentation of data. The fifth part pertains to the discussion and finally the recommendations are presented that can help ensure that internship becomes a valuable path of learning for students in the DLLCE at UNAM.

\section{Statement of the Problem}

The Namibian Office of the President and the National Planning Commission (2006) (Namibia. Office of the President, 2012) declare that an internship in organisations helps to ensure that institutions of higher learning provide the skills and knowledge required for work. Therefore, Internship is the most appropriate learning option to enhance graduates' technical knowledge. However, the students in the DLLCE at UNAM do not seem to perceive it as an approach to learning, but as a set of tasks to be undertaken rather than the learning that those 
tasks represent. Moreover, the internship process places the student interns in a position where they are required to balance the requirements of their academic development and their new role as interns at selected organizations. It is against this background that the present study sought to unearth the challenges and student views on measures for internship among fourth-year students in the DLLCE at UNAM. The study also sought to find adequate literature measures that could be adopted to address the challenges students face while on internship and how internship can become a valuable tool for learning. The following research questions were developed to address the research problem:

- What academic and logistical challenges do students of lifelong learning and community education experience while on internship?

- What measures should be applied to ensure that internship becomes a valuable path of learning among students in the Department Lifelong learning and Community Education at the University of Namibia?

- What knowledge and skills from the DLLCE are required to make internship effective among students in the Department Lifelong learning at the University of Namibia?

\section{The Conceptual-Theoretical Framework}

The concepts of "internship" and "learning through practice" are significant in the empirical part of this paper. These concepts are explained to understand the context within which they are used. The manner in which these concepts become linked to the experiential learning theory which informs this study is also explained.

The term internship is used to refer to an opportunity offered to undergraduate students in the DLLCE to work at a firm or an organization for a limited period of time (Nohara, Norton, Saijo, \& Kusakabe, 2008). This is because "internship" as used here is premised on the trajectory of adult learning proposed by Jarvis (1995), who suggests a model that allows different routes of learning for adults. According to Jarvis, adults learnt "through practise", "observation" and through "lecture methods". Learning through practise is the act or process of acquiring knowledge or skill and modification of behaviour through practise, training, or experience. Brookfield (1986) emphasizes that adults' personal experience is a rich learning resource that they can use in self-directed learning endeavour. To him the idea of practical, self-directed learning blended with the reinforcement of correct behaviour make adult learning worthwhile. The authors of this paper are of the view that since internship offers on-the-job training meant to expose students to real work conditions; it should be perceived as the provision of an opportunity for undergraduate students to learn through concrete practise, by engaging in assimilations of the work tasks as performed in organizations by site employees.

This study is informed by experiential learning theory because it provides perspective from which to approach learning through practise during the internship. 
The experiential learning theory emphasizes the central role that experience plays in the learning process (Kolb, Boyatzis, \& Mainemelis, 1999). In addition, the afore-mentioned elucidations, authors define learning as the process whereby knowledge is created through the transformation of experience. Adjei, Nyarko, \& Nunfam (2012) explain the two complementary views of experiential learning, one being the opportunity afforded to students to acquire and apply knowledge and skills in an immediate and relevant environment; the other describes the educational process that occurs as a result of direct participation in the events of life. This study follows the first option of experiential learning which permits students to apply theoretical knowledge in the workplace.

Experiential learning operates on the assumption that effective learning takes place when a person progresses through a cycle of four stages such as concrete experience, reflective observation, abstract conceptualisation and active experimentation, as exhibited in Figure 1. The idea behind the experiential theory in this study is taken from the rationale that students have undergone theoretical studies on how learning takes place outside the classroom. Thus, the service learning/internship is organised to give students a practical hands-on experience of actual performance.

Figure 1 emphasizes the development of concrete experience. Billet (2005) asserts that work-based experiences generates occupational knowledge and concepts not restricted to learning needed in the particular workplace setting, but also skills that can be applied elsewhere. Billet maintains that knowledge learnt in institutional programmes does not always adapt or transfer adequately to the

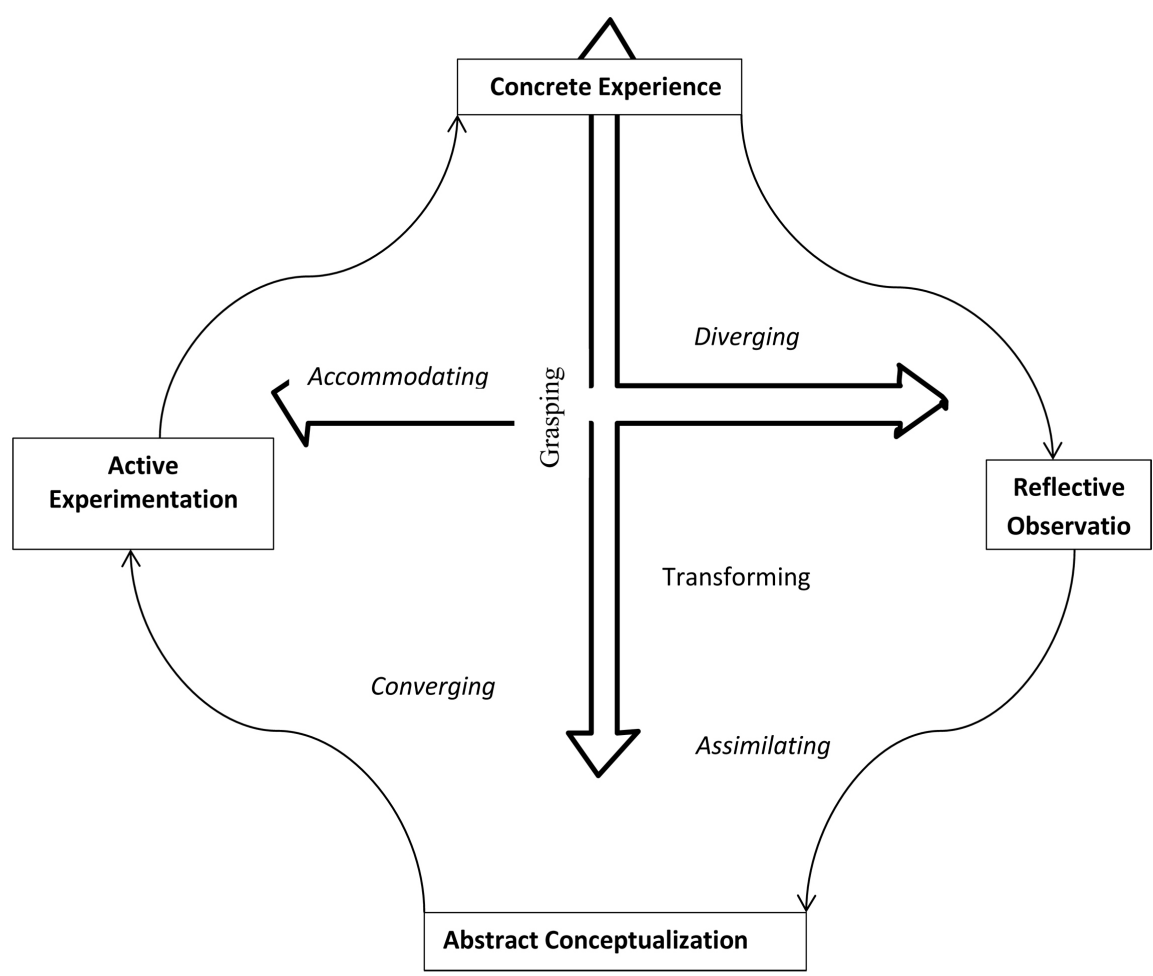

Figure 1. The four stages of the experiential learning theory (Kolb \& Kolb, 1999). 
world of work and needs practice to yield a mix of theory and practice. The student acquires concrete experience whereby he/she obtains actual experience of performing the task. There is also reflective observation (RO), where the intern watches mentors on site as they perform various tasks, listens to practical complaints or motivations about tasks, views issues from different points of view, and discovers meaning from the learning material. Abstract Conceptualization (AC) is the application of thought and logic, as opposed to feelings, to the learning situation. In fact, the experiential learning theory is about the exposing students to real work activities embedded in the work environment and those which classroom knowledge alone cannot provide. Kolb et al. (1999) call experiential learning a molar concept describing the central process of human adaptation to the social and physical environment through direct experience. In this tradition, knowledge is a result of a transaction between social knowledge, what is known in industries about a specific issue, and academic knowledge emanating from the classroom. Therefore, this theory advocates for the combination of learning routes and provides an excellent transformational device for active experimentation.

The study to explore the challenges and measures for internship among fourth-year students in the DLLCE at UNAM integrated the following characteristic of experiential learning, borrowed from Kolb and Kolb (1999):

- Learning is best conceived as a process, not in terms of outcomes. Therefore, to improve learning through practise, there is a need to engage the students in a process that best enhances their learning. This process should give feedback on the effectiveness, challenges and measures for internship among fourth-year students of their learning efforts.

- All learning is re-learning. Learning through practise is best facilitated by a process that draws out the students' ideas about an internship so that these ideas are integrated with new, more refined ideas.

- Learning is a holistic process of adaptation. It is not only the result of cognition, but also involves the integrated functioning of the total person-thinking, feeling, perceiving and behaving. It encompasses other specialized models of adaptation from the scientific method to problems-solving, decision-making and creativity.

- Learning results from synergetic transactions between the students and the environment. Stable and enduring patterns of human learning arise from consistent patterns of transaction between the individual and his or her environment. The way we process the possibilities of each new experience determines the range of choices and decisions we see. The choices and decisions made, to some extent determine the events we live through, and these events influence our future choices. People therefore create themselves through the choice of actual occasions they live through.

- Learning is the process of creating knowledge. This proposes a constructivist theory of learning whereby knowledge is created and recreated through 
students' experience. This stands in contrast to the "transmission" model on which educational practice is based, where pre-existing fixed ideas are transmitted to the students.

Based on the above conceptual-theoretical framework, this study was conducted to explore the challenges and measures for internship among fourth-year students in the DLLCE at UNAM.

\section{Research Design and Methods}

The study followed a mixed method approach because it employed aspects of qualitative and quantitative research procedures (Creswell, 2012). The mixed method design was generally significant in this study in order to obtain statistical results while qualitative procedures helped explain the results in more depth. The study therefore followed a sequential exploratory strategy to apply the mixed methods research design (Hanson et al., 2005), because it collects and analyses both the qualitative and quantitative data and gives priority to the qualitative data (Ibid). The quantitative data was analyzed first, followed by the analysis of the qualitative data. However, the quantitative data was used primarily to augment qualitative data. The survey method used a structured questionnaire to assess the academic and logistical difficulties the students encountered during internship. The quantitative data intended to collect data of the types of difficulties encountered in work places and regions where the internships took place. The phenomenological method used an interview guide to solicit views and experiences pertaining to measures and the knowledge and skills needed to make the internship exercise effective among interns at the DLLCE at UNAM.

\subsection{Population, Sample and Sampling Procedures}

Population includes all the fourth-year students in the DLLCE at UNAM who were enrolled for internship in 2015. A convenience sampling strategy was employed to sample the fourth-year students in the DLLCE who were available when the questionnaire was distributed. Of the 32 students in their fourth year, 29 were available and willing to participate in the study.

\subsection{Data Collection Procedures, Research Instruments and Ethical Considerations}

Students completed a 12 weeks internship in various regions of the country. On the first day of their return to class, a researcher informed them that a questionnaire would be distributed on the following day after class. The information was purposely given to seek student consent and to give those not interested in completing the questionnaire the opportunity to leave the class before administration of the questionnaire. On the following date, the questionnaire was distributed to the students who volunteered. The questionnaire contained two sections which had to be completed. Section 2 was close-ended while the second part solicited open-ended views and opinions. Upon completion, the researchers collected the 
completed questionnaire.

The ethical clearance was sought from the Head of Department of DLLCE as it is required by the UNAM policy that the undergraduate ethical review be granted by departmental. Permission was also sought from the fourth-year students themselves to participate in the research. The purpose of the study was explained to them, autonomy and privacy were ensured so that information would not portray the individual names of participating students. The data reflects the opinions of units of analysis rather than individual students. All students willingly gave their consent and understood that they were free to refuse to complete the questionnaire.

\subsection{Data Analysis}

Quantitative data was captured and analyzed using the Statistical Package for Social Sciences (SPSS). The SPSS spread sheets were exported to Microsoft Excel to generate the graphs depicting quantitative data. The statistics included the tallying of frequencies in the calculation of percentages. Qualitative data was transcribed and analyzed using cross-case analysis (Patton, 1990). During the cross-case analysis, answers from different participants to a question were grouped and labelled using Nvivo codes, which were the actual participants' words pertaining to writing, leadership skills and management skills. Moreover, the Inductive analysis process was employed. This analysis helped to generate patterns, categories and themes from the data. The themes that emerged included the measures by UNAM students, orientations, knowledge required, agreements and the internship process.

\section{Presentation and Interpretation of Results}

The following is a logical representation of topics from the questionnaire.

- Regions and sectors where internship was undertaken.

- Challenges experienced by interns while on internship.

- The measures to ensure that internship becomes a valuable path of learning among fourth-year students in the DLLCE.

- The knowledge and skills required to make internship effective among fourth-year students in the DLLCE.

\subsection{Regions and Sectors where the Internship Was Undertaken}

The participants were asked to state the regions where they did the internship and the results are presented in Figure 2.

It seems that the majority of students embark on their internship in the Khomas region. This was followed by students in the Ohangwena and Omaheke regions. Other regions of Namibia that hosted students' internship included the Erongo, Omusati and Oshana regions. On the whole, these results indicate that students embarked on their internship in nine out of 14 regions of Namibia.

The participants were asked to state the sector where they did the internship and the results are presented in Figure 3. 


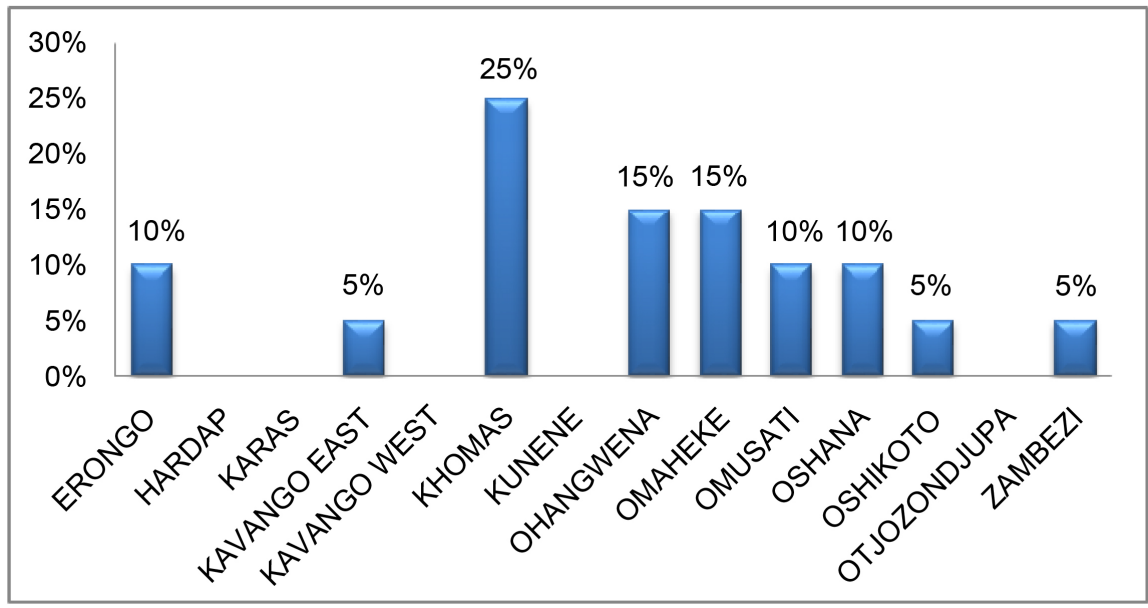

Figure 2. Regions where internship was undertaken by fourth-year students of DLLCE.

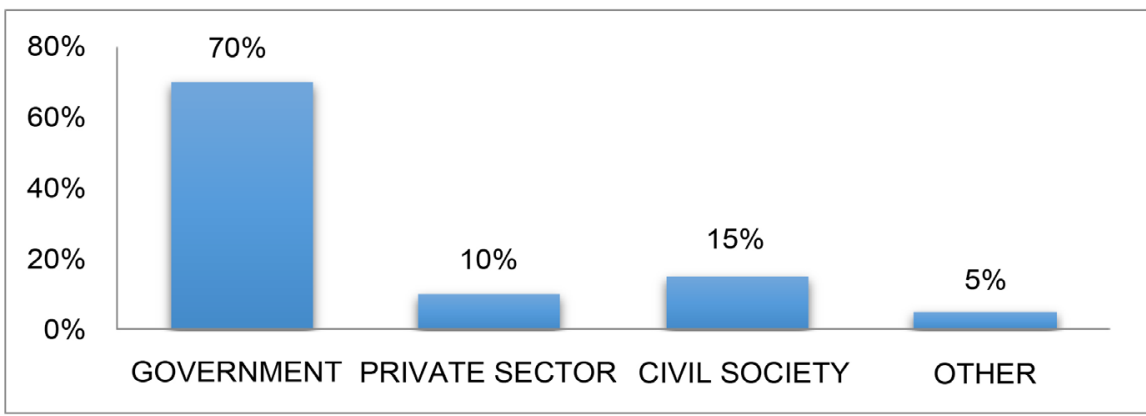

Figure 3. Sectors where internship took place among fourth-year students of DLLCE.

The majority of students embarked on the internship in the government sector because of them were unpaid internships meant to provide educational opportunities to the interns. The government sector was followed by students who embarked on their internship in civil society. Other students undertook their internship in the private sector where the interns would have been paid allowances. The other sectors included faith-based organizations and the United Nations Agencies. On the whole, these results indicate that students embarked on their internship in different sectors of the Namibian economy.

\subsection{Academic Challenges Faced by Fourth-Year Students on Internship}

The students were asked to indicate academic-related challenges they faced during internship and the results are presented in Figure 4.

Figure 4 shows that the main academic difficulties students experienced were lack of material to complete assignments and lack of support from the internship agency. A small percentage of students also experienced a lack of support from the academic supervisor. It seems that some students experienced all of these problems while a few did not experience any challenges.

The students were asked to specify the logistical difficulties and challenges they faced while on internship and the results are presented in Figure 5. 


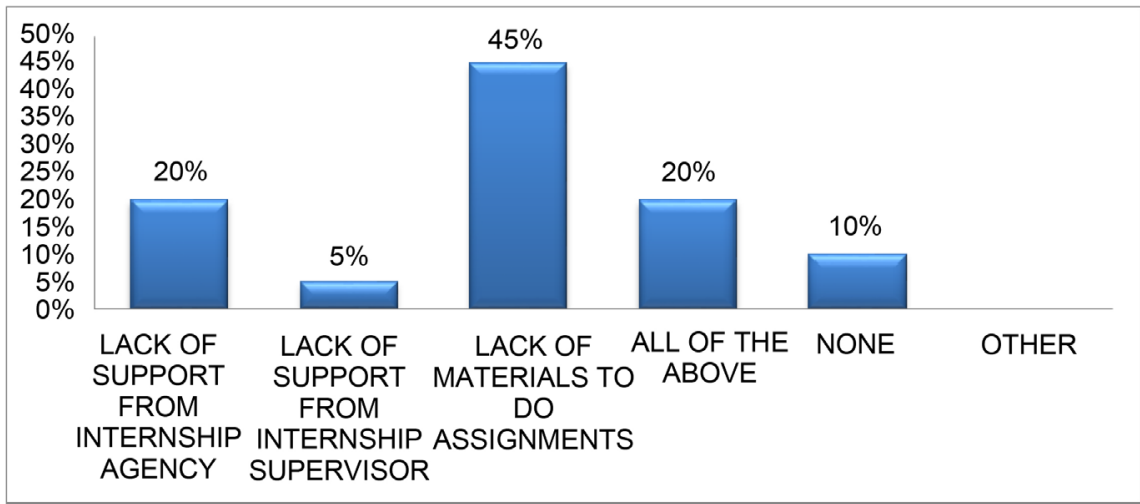

Figure 4. Academic challenges faced by fourth-year students on internship.

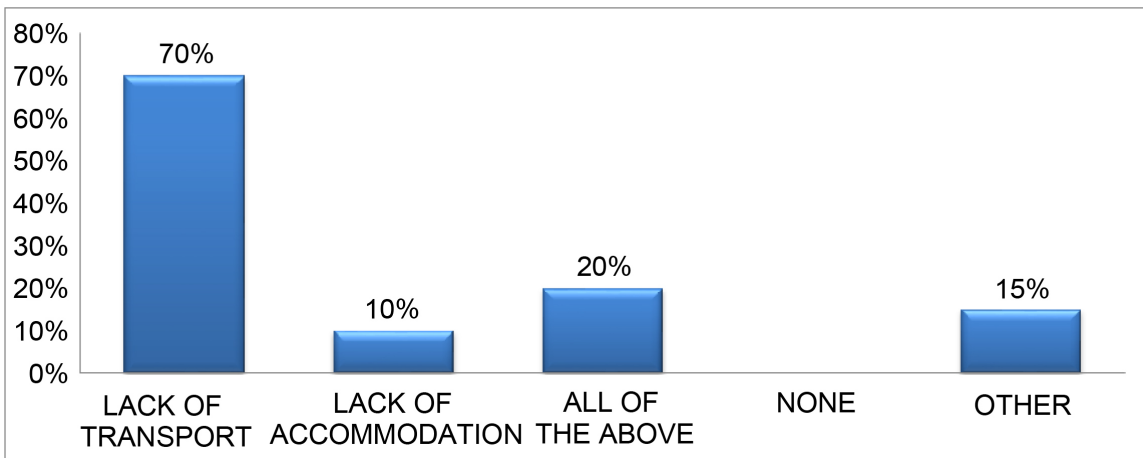

Figure 5. The logistical challenges faced by fourth-year students on internship.

Figure 5 shows that the main logistical difficulty students experienced was lack of transport. This applies to those students who embarked on their internship outside Windhoek. Lack of accommodation was also mentioned by students who needed to pay rent during internship.

\subsection{The Measures to Ensure that Internship Becomes a Valuable Path of Learning}

The students were asked to explain the measures that should be applied to ensure that internship becomes a valuable path of learning among students in the DLLCE at UNAM. The results are presented in Table 1.

The data revealed four categories of measures that should be applied to ensure that internship becomes a valuable path of learning among students in the DLLCE at UNAM. The first category of measures pertains to orientation. This relates to the need to explain to the interns the roles of the agency and those of the supervisors, both at the internship site and at the university. Students also expressed the need for clear instructions and guidelines during internship, as well as activities expected from them.

The second category of measures expresses the need to expand knowledge required and to understand the science of learning through practise. They needed to understand how they could translate what they had learnt in the classroom into tasks performed in the agencies. Students stressed that site supervisors did 
Table 1. Measures to ensure that internship becomes a valuable path of learning among students in the Department Lifelong Learning at the University of Namibia.

\begin{tabular}{|c|c|}
\hline Measures & Description of measures \\
\hline Orientations of students & $\begin{array}{l}\text { - } \text { Roles of students } \\
\text { - Roles of Agency } \\
\text { - Roles of UNAM staff } \\
\text { - } \text { Roles of supervisor at agencies } \\
\text { - } \text { Activities to be expected at agencies }\end{array}$ \\
\hline Knowledge required & $\begin{array}{l}\text { - Learning through practise } \\
\text { - Internship (attachments) } \\
\text { - Handling community members (community leaders) }\end{array}$ \\
\hline Agreement & $\begin{array}{l}\text { - Identification of agencies } \\
\text { - Outlining activities for students } \\
\text { - Negotiating details of internship (e.g. payment, indemnity) } \\
\text { - Which agencies relate to DLLCE }\end{array}$ \\
\hline Internship process & $\begin{array}{l}\text { - Students' money } \\
\text { - Availability of study materials } \\
\text { - Assignments } \\
\text { - Registration while on internship }\end{array}$ \\
\hline
\end{tabular}

not have an understanding of what adult and community education was about and did not know the role of interns in the work places. One student intern stated that "Internship supervisors don't understand what adult education is, what our roles are, duties and areas of specialization". Hence, the site supervisors' understanding of adult education is that it comprises basic literacy skills being offered by the Ministry of Education.

The third category of measures that should be applied to ensure that internship becomes a valuable path of learning among students in the DLLCE pertains to agreement. This entails that the University and the Department enter into a formal agreements with agencies and organisations to which students can be attached. Students stated that some organisations refused to attach them because they did not have an agreement with UNAM. One student complained that: It is very disappointing when a student is refused by an organization on the basis that UNAM has not signed an agreement with the said organization. Another student stated that:

Good communication skills are needed between the site supervisor and the student as well as between the internship supervisor and UNAM. This will allow the site supervisor to allocate tasks related to students' skills.

The last category of measures is about ensuring that internship process becomes as a valuable path for learning. All students who answered this question stressed the need for adequate preparation prior to students departing for the field. Since internship takes place during lecture sessions, students stated that assignments for various subjects and learning materials were not always ready when they arrived at the field. Their refunds from the university were always 
late, registration took place while students were on internship and this created misunderstandings.

\subsection{The Knowledge and Skills Required to Make Internship Effective among Students in the Department Lifelong Learning and Community Education at the University of Namibia}

The participants were asked to present the knowledge and skills required to make internship effective among students in the DLLCE at UNAM and the responses are reported in Table 2.

The data depicts three different kinds of skills that interns expressed as measures needed to make internship effective: firstly, writing skills, ranging from taking minutes, report writing, applications, and writing proposals; secondly, leadership skills. Students felt they needed knowledge about team work, communication, problem-solving, liaising skills, interrelations and technology; thirdly, management. Interns indicated that they needed more knowledge about time management, management of people such as co-workers, anger management, evaluation skills and self-management. Interns stated the following: Lecturers should put more emphasis in teaching how to write reports and do presentations using various forms of technology, and provide skills of good communication, team work, time and anger management as well as self-discipline are required skills necessary to facilitate internship exercise.

In general, interns felt they were not well prepared for the world of work, because they were not adequately conversant in skills and knowledge required in

Table 2. The knowledge and skills required to make internship effective among students in the Department Lifelong Learning at the University of Namibia.

\begin{tabular}{|c|c|}
\hline Skills and knowledge areas & Description \\
\hline Writing skills & $\begin{array}{ll}\text { - } & \text { Minute taking } \\
\text { - } & \text { Report writing } \\
\text { - } & \text { Letter writing } \\
\text { - } & \text { Proposal writing }\end{array}$ \\
\hline Leadership skills & $\begin{array}{l}\text { - } \text { Team work } \\
\text { - Presentation } \\
\text { - Facilitation } \\
\text { - Communication } \\
\text { - Problem-solving } \\
\text { - Liaison } \\
\text { - Interrelations } \\
\text { - Technology }\end{array}$ \\
\hline Management skills & $\begin{array}{ll}\text { - } & \text { Time management } \\
\text { - } & \text { Manage people (co-workers and supervisors) } \\
\text { - } & \text { Manage projects } \\
\text { - } & \text { Evaluation skills } \\
\text { - } & \text { Self -management (discipline) }\end{array}$ \\
\hline
\end{tabular}


workplaces such as those cited in Table 2.

\section{The Discussion}

The participants in this study were fourth-year students in the DLLCE at UNAM. It seems that two-thirds of the regions of Namibia were covered. The Khomas region of Namibia recorded the highest number of interns compared to other regions. This can be attributed to the fact that the University is situated in the Khomas region and as such it was easy for students to reach the sites of internship situated in that region.

The academic challenges that these fourth-year students experienced while on internship were cited. The first challenge pertained to alack of support from the internship supervisor. This challenge is management-oriented because it is about the measures that the institution of internship must put in place to support student interns. It seems that most of the organizations were not aware of the rules of the Public Service Commission emanating from the Namibian Office of the Prime Minister, which maintain that students should be afforded appropriate and adequate supervision while on internship. The second challenge pertained to the lack of materials to do assignments. This challenge stems from departmental lecturers that do not seem committed to provide assignments and study materials on time. The Office of the Prime Minister (2006: p. 5) states that students on internship in the public service of Namibia must be assigned "activities and full functions that are relevant and commensurate with the level of such internship". This really seems to indicate that supervisors at higher education institutions and at agencies need to plan and prepare activities to be given to interns. The Office of the Prime Minister (Namibia, Office of the Prime Minister, 2006) stipulates that the supervisor should act as mentor during internship with a base of knowledge and experience in the specific field of study of the intern, so as to give the type of exposure demanded by the programme. Thirdly, the interns also indicated a lack of support from the internship agencies, which could illustrate a lack of coordination between institutions of higher learning and the agencies of attachment. With collaboration, students would be inducted into the activities of the organization and assigned to appropriate functions.

The logistical challenges that fourth-year students experienced while on internship relate to the lack of transport and accommodation. These seem real barriers that should be addressed but it is important to coach students to understand the principles of adult learning, which maintain the need for students to control and manipulate processes that contribute to their own learning. For example, Garrison (1997) refers to the concept of self-directedness where the students are motivated to assume personal responsibility for the contextual processes in confirming and constructing a meaningful learning process. Therefore, it seems that there is a real need for students to become self-directed learners in that they should be urged to assume responsibility for processes pertaining to their own accommodation and transportation to places of internship. One way 
of assisting them, according to the interns, is to ensure that they are encouraged to disclose to the site supervisor the accommodation that is available.

The knowledge and skills required to make internship effective among fourth-year students of DLLCE include writing skills, leadership skills and management skills. The agencies of attachment seem to expect interns to be knowledgeable of the basic skills employed at agencies, such as taking minutes, report writing, some level of facilitation skills and some understanding of leadership skills. Moreover, writing skills express the importance of communication in developing personal and interpersonal competencies. Bhattacharyya, Nordin and Salleh (2009) argue that communication skills are recognized and acknowledged as indispensable by stakeholders from both the industry and education sectors. Moreover, personal or interpersonal competency includes stress management, motivating others and conflict management (Clark, 2009).

\section{Recommendations and Implications for Policy and Teaching Practice in the Department}

The following recommendations are made for improvement of the internship exercise:

- It seems that there is a real need to orientate fourth-year students when they are about to embark upon an internship. The orientation should be based on the experiential theory outlined above. It therefore is important to include students in defining their roles during internship, the roles of the agency and the activities expected from them during the internship. Moreover, the orientation should explain how to balance academic development with their new role as interns at selected organizations.

- The internship process could be more explicit. This process must include the specification of financial arrangements to be made by students, availing study materials on time and assignments as well as clarifying registration matters through the faculty office.

- It seems that there is a need to promote the qualities of being a self-directed learner when it comes to students' accommodation and transport. This means that students should be urged to take responsibility for acquiring accommodation and transport following principles of adult learning. However, support could be provided in some circumstances. For example, it could be best to encourage students to disclose to the site supervisor early in the process the accommodation that may be available so that support may be sought from the site supervisor in that regard.

- It seems that there is a need to strengthen learning content pertaining to leadership and management courses in the DLLCE. This could be appropriated in two ways. Firstly, there is the need to strengthen the course content on management of adult education to ensure that it embraces team work, facilitation skills, problem-solving and relational skills. This should include time management, emotional intelligence as well as project monitoring and 
evaluations.

- It seems that there is a need to provide assessment and assignments that relate to leadership and management by asking students to explain how team work, facilitation skills, problem-solving and relational skills were embraced during the internship period. These assignments would help students to understand how to apply and transfer the knowledge gained from leadership and management courses into the places of internship.

- The writing skills course should be developed and integrated into the Bachelor of Education course. To this end, it seems that there is a need to teach students the art and skills of minute taking, report writing, formal letter writing and proposal writing through the English language course.

- The DLLCE should use the UNAM's office of External and International Relations to enter into formal agreements with the agencies of attachment. This would help to align mandates of the internship agencies and the mandate of the university. It would also help students to identify the agencies that relate to the DLLCE. The process may help to address the academic and logistical issues that face both interns and university supervisors.

- The lecturers in the department should be urged to provide assignments to students well ahead of time to maximize learning during the internship. Briel and Getzel (2001) provide strategies that can be utilized to improve the success of students on internships. These include initial feedback from site supervisors and urging them to familiarize themselves with the instructional strategies of academic programmes and assignments.

- The internship reports should be continuously evaluated in terms of the extent to which the students acquired writing, leadership and management skills. It should be emphasized that internship is best conceived as a process and not an outcome. It seems very important to urge interns to make a self-evaluative reflection on these accompaniments of the knowledge and skills that, according to them, are needed.

The implementation of the above recommendations should be guided by the experiential learning theory. Firstly, it should be noted that internship is a form of learning that should be conceived as a process and as such re-learning should be integrated. According to these students, there is need for them to understand how they can translate what they have learnt in the classroom into tasks performed in the agencies. The site supervisors seem that they do not have an understanding of what adult and community education is about and understands the role of interns in the work place. This should be integrated in a continuous process of dialogue that draws out the students' ideas to enhance transactions between the students on internship and the environment.

\section{Conclusion}

This paper reports on the challenges and measures for internship among fourth-year students in the DLLCE at UNAM. According to the interns, the 
logical challenges relate to transport and accommodation while the academic challenges concern the lack of support from supervisors in the workplace as well as the academic support supervisor from the DLLCE. It seems that there is urge to promote the qualities of being self-directed, which means that the students must be urged to assume responsibility for controlling and manipulating processes which contribute to their own learning. They should be encouraged to assume control pertaining to transport and accommodation. According to the interns, the skills and knowledge that they need are writing, leadership and management skills. These skills should be developed and integrated into the Bachelor of Education programme and the interns should be given an opportunity to show the extent to which they acquired these skills by giving them space to reflect on these aspects in their reports. Student interns also seem to profoundly need to come to an agreement with agencies to do an internship. The purpose of internship is to provide students with practical experience that can complement interns' acquired theoretical knowledge and any other classroom-based learning. Hence it is important to orientate fourth-year students when they go on internship. The orientation processes must define the roles of students, roles of the agency and the activities expected from students during the internship. The definition of roles of students and that of the agency and other related agencies must be based on the experiences of the students. The DLLCE needs to utilise the university office of External and International Relations to enter into formal agreements with agencies of attachment. This would help to align mandates of the internship agencies and the mandate of the university. It would also help students to identify the agencies that relate to the DLLCE.

\section{References}

Adjei, N. A. K., Nyarko, D. A., \& Nunfam, V. F. (2014). Industrial Attachment in Polytechnic Education: An Approach to Polytechnic-Industry Nexus in Human Capital Development of Selected Polytechnics in Ghana. Journal of Education and Practice, 5, 33-49.

Bhattacharyya, E. B., Nordin, S. M., \& Salleh, R. (2009). Internship Students' Workplace Communication Skills: Workplace Practices and University Preparation. Florida: American Society for Engineering Education. http://www.indiana.edu/ ciec/Proceedings_2009/Papers/ETD/ETD555_Bhattacharyya. pdf

Billet, S. (2005). Learning through Practice: Beyond Informal and towards a Framework for Learning through Practice.

http://www.unevoc.unesco.org/.../2013_epub_revisiting_global_trends_in_tvet_chapter $\underline{4 . p}$

Briel, L. W., \& Getzel, E. E. (2001). Internships in Higher Education: Promoting Success for Students with Disabilities. Disability Studies Quarterly, 21, No. 1. http://www.dsq-sds.org/article/view/254/257

Brookfield, S. (1986). Understanding and Facilitating Adult Learning: A Comprehensive Analysis of Principles and Effective Practices. Buckingham: Open University Press.

Clark, S.C. (2009). Enhancing the Educational Value of Business Internships. Journal of Management Education, 27, 472-484. https://doi.org/10.1177/1052562903251350 
Creswell, J. W. (2012). Educational Research: Planning, Conducting and Evaluating Quantitative and Qualitative Research. Boston, MA: Pearson.

Garrison, D.R. (1997). Self-Directed Learning: Toward a Comprehensive Model. Adult Education Quarterly, 48(1), 18-33. https://doi.org/10.1177/074171369704800103

Hanson, W. E., Vicki, L., Clark, V. L. P., Kelly, S., Petska, K. S., \& Creswell, D. J. (2005). Mixed Methods Research Designs in Counselling Psychology. Journal of Counselling Psychology, 52, 224-235. https://doi.org/10.1037/0022-0167.52.2.224

Jarvis, P. (1995). Adult and Continuing Education: Theory and Practice (2nded.). London: Routledge.

Kolb, A. Y., \& Kolb, D. A. (1999). Experiential Learning Theory: A Dynamic, Holistic Approach to Management Learning, Education and Development. https://weatherhead.case.edu/departments/organizational-behavior/workingPapers/W P-07-02.pdf

Kolb, D. A., Boyatzis, R. E., \& Mainemelis, C. (1999). Experiential Learning Theory: Previous Research and New Directions. Cleveland: Case Western Reserve University. https://www.d.umn.edu/ kgilbert/educ5165-731/Readings/experiential-learning-theor y.pdf\#page $=2 \&$ zoom $=$ auto, $-121,759$

Lauber, C. A., Ruh, L., Theuri, P. M., \& Woodlock, P. (2004). Road to the Future: Use Internships to Contribute the Younger Generation and Get a Good Look at Potential Hires. Journal of Accountancy, 198, 41.

Namibia, Government (1992). University of Namibia Act 18 of 1992. Windhoek: Government of Namibia.

Namibia, New Era New Paper (2015). Is Vision 2030 Attainable? https://www.newera.com.na/2015/07/10/vision-2030-attainable/

Namibia, Office of the President (2004). Namibia Vision 2030: Policy Framework for Long-Term National Development. Windhoek: Office of President.

Namibia, Office of the President (2012). National Human Resources Plan 2010-2025. Windhoek: Office of the President.

Namibia, Office of the Prime Minister (2006). Framework for the Student Internship in the Public Service of Namibia. Windhoek: Office of the Prime Minister.

National Planning Commission (2006). Namibia Household Income\& Expenditure Survey: Main Report. Windhoek: Central Bureau of Statistics: National Planning Commission.

Nohara, K., Norton, M., Saijo, M., \& Kusakabe, O. (2008). Overseas Internships as a Vehicle for Developing a Meta-Level Awareness Regarding Science Communication. Journal of Science Communication, 7, 1824-2049.

Patton, M. Q. (1990). Qualitative Evaluation and Research Methods (2nd ed.). Beverly Hills, CA: Sage.

UNAM-Centre for Quality Assurance and Management [CEQUAM] (2012). Quality Assurance and Management Policy of the University of Namibia. Windhoek: UNAM. 